\title{
The Amyloid, Tau, and Neurodegeneration (A/T/N) Classification Applied to a Clinical Research Cohort with Long-Term Follow-Up
}

\author{
Gøril Rolfseng Grøntvedta ${ }^{\mathrm{a}, \mathrm{b}, *}$, Camilla Lauridsen ${ }^{\mathrm{a}}$, Guro Berge ${ }^{\mathrm{b}}$, Linda R. White ${ }^{\mathrm{a}, \mathrm{b}}$, \\ $\emptyset_{\text {yvind Salvesen }}{ }^{\mathrm{c}}$, Geir Bråthen ${ }^{\mathrm{a}, \mathrm{b}}$ and Sigrid Botne Sando ${ }^{\mathrm{a}, \mathrm{b}}$ \\ ${ }^{a}$ Department of Neurology and Clinical Neurophysiology, University Hospital of Trondheim, Trondheim, Norway \\ ${ }^{\mathrm{b}}$ Department of Neuromedicine and Movement Science, Faculty of Medicine and Health Sciences, Norwegian \\ University of Science and Technology, Trondheim, Norway \\ ${ }^{\mathrm{c}}$ Unit for Applied Clinical Research, Faculty of Medicine and Health Sciences, Norwegian University of Science \\ and Technology, Trondheim, Norway
}

Accepted 21 January 2020

\begin{abstract}
.
Background: The unbiased amyloid, tau, and neurodegeneration (A/T/N) classification is designed to characterize individuals in the Alzheimer continuum and is currently little explored in clinical cohorts.

Objective: A retrospective comparison of the A/T/N classification system with the results of a two-year clinical study, with extended follow-up up to 10 years after inclusion.

Methods: Patients $(n=102)$ clinically diagnosed as Alzheimer's disease (AD) with dementia or amnestic mild cognitive impairment (MCI), and 61 cognitively healthy control individuals were included. Baseline cerebrospinal fluid core biomarkers for $\mathrm{AD}\left(\mathrm{A} \beta_{42}\right.$, phosphorylated tau, and total tau) were applied to the $\mathrm{A} / \mathrm{T} / \mathrm{N}$ classification using the final clinical diagnosis at extended follow-up as the gold standard.

Results: $\mathrm{A}+\mathrm{T}+\mathrm{N}+$ was a strong predictor for $\mathrm{AD}$ dementia, even among cognitively healthy individuals. Amnestic MCI was heterogenous, considering both clinical outcome and distribution within A/T/N. Some individuals with amnestic MCI progressed to clinical $\mathrm{AD}$ dementia within all four major $\mathrm{A} / \mathrm{T} / \mathrm{N}$ groups. The highest proportion of progression was among triple positive cases, but progression was also common in individuals with suspected non-Alzheimer pathophysiology (A$\mathrm{T}+\mathrm{N}+$ ), and those with triple negative status. A-T-N- individuals who were cognitively healthy overwhelmingly remained cognitively intact over time, but in amnestic MCI the clinical outcome was heterogenous, including AD dementia, other dementias, and recovery.

Conclusion: The A/T/N framework accentuates biomarkers over clinical status. However, when selecting individuals for research, a combination of the two may be necessary since the prognostic value of the $\mathrm{A} / \mathrm{T} / \mathrm{N}$ framework depends on clinical status.
\end{abstract}

Keywords: Alzheimer's disease, amyloid, biomarkers, cerebrospinal fluid, classification, mild cognitive impairment, tau

\footnotetext{
*Correspondence to: Gøril Rolfseng Grøntvedt, MD, Department of Neuromedicine and Movement Science, Norwegian University of Science and Technology, NO-7030 Trondheim, Norway. Tel.: +47 725768 87; E-mail: goril.r.grontvedt@ntnu.no.
} 


\section{INTRODUCTION}

Alzheimer's disease (AD) is the most prevalent neurodegenerative disorder comprising 50-60\% of dementia cases. With an aging population, the number of people with dementia worldwide is expected to quadruple by 2050 unless effective treatment or prevention becomes available [1]. It is now accepted that AD is a continuum and probably begins at least 15-20 years before symptom onset $[2,3]$. During the last 15 years, research has moved increasingly toward the pre-dementia phase of $\mathrm{AD}$, particularly mild cognitive impairment (MCI), during which there is a measurable loss of cognitive ability and some brain atrophy, but the patient is still capable of independent living. Criteria for MCI were presented in 2004 [4], and the type most often converting to $\mathrm{AD}$ is the amnestic form, where memory is affected. Detailed information on the progression process will be essential when effective treatment that hinders development of the disease becomes available. Society as a whole will also benefit since a 5-year delay in dementia onset has been estimated to reduce the number of dementia cases by $57 \%$ [5].

Clinical evaluation and cognitive test batteries alone frequently fail to provide the clinician with a precise diagnosis of AD [6]. The National Institute on Aging and Alzheimer's Association (NIA-AA) Alzheimer's Diagnostic Framework introduced a new, unbiased classification system in 2016 to apply validated biomarkers for the separation of $\mathrm{AD}$ from non-AD causes of impaired cognition. The classification uses three types of biomarkers to determine the extent of pathology typical of AD: A (amyloid, represented either by cerebrospinal fluid (CSF) levels of amyloid- $\beta 42\left(\mathrm{~A} \beta_{42}\right)$ or amyloid plaque deposition in brain as seen with amyloid-PET); $\mathrm{T}$ (tau, measured as the level of CSF hyperphosphorylated tau (p-tau) or tangle-formation as seen by tau-PET); and $\mathrm{N}$ (neurodegeneration as shown by structural MRI, CSF levels of total tau (t-tau), or brain metabolism as measured with fluorodeoxyglucose (FDG-PET)). The framework thereby characterizes the AD spectrum by its biological presentation, and is independent of clinical assessment of cognitive status. It has been designated the $\mathrm{A} / \mathrm{T} / \mathrm{N}$ classification system and individuals can be classified as positive (+) or negative (-) for $\mathrm{A}, \mathrm{T}$ and $\mathrm{N}$, resulting in 8 possible A/T/N profiles [7].

The aim of this study was to explore the distribution of the $\mathrm{A} / \mathrm{T} / \mathrm{N}$ classification system in a clinical cohort and evaluate agreement with long term clinical outcome.

\section{MATERIALS AND METHODS}

\section{Ethics}

The present study was conducted according to the Helsinki Declaration. Written, informed consent was obtained from all patients or suitable proxies, and from all control individuals. The Trønderbrain Biobank has been licensed by the Norwegian Directorate for Health Affairs, and the research was approved by the Regional Committee for Medical Research Ethics (2010/226 REK Midt).

\section{Subjects}

The demographic and associated data for the study cohort are shown in Table 1. A total of 102 patients were recruited through the Department of Neurology, University Hospital of Trondheim, by two neurologists with specialization in dementia disorders (SBS and GRG). Patients were included between 2009 and 2013 and were diagnosed as either having AD with dementia according to the NINCDS-ADRDA criteria [8], or amnestic MCI according to the International Working Group on Mild Cognitive Impairment Criteria [9]. Diagnosis was determined blind to biomarker concentrations in all cases.

All patients were ethnic Norwegians between 54-78 years of age. General exclusion criteria were insufficient sight and hearing to complete the cognitive testing, a present psychiatric or malignant disease, use of anti-coagulating medication, or high alcohol consumption.

The control population consisted of 61 elderly volunteers between 57-84 years of age. They were recruited from societies for retired people in central Norway and assessed as being cognitively healthy for their age without signs of neurological disorders. Neurological examination, blood screening, and cognitive tests were performed on all participants, including the Mini-Mental State Examination (MMSE) [10], the CERAD Ten-Word Test (TWT) with delayed recall, as taken from ADAS Cog [11], Trailmaking test A and B [12], as well as cerebral 3T MRI at baseline and after two years. APOE genotyping was performed on blood samples according to the method described elsewhere [13].

Study participants were initially monitored over a period of two years. During this time, almost half 
Table 1

Demographic data of the clinical groups at baseline

\begin{tabular}{lccc}
\hline Diagnosis & AD dementia & Amnestic MCI & Healthy individuals \\
\hline $\mathrm{N}$ & 38 & 64 & 61 \\
Gender female $(\%)$ & $20(52.6)$ & $34(53.1)$ & $40(65.6)$ \\
Age (y) & $63.5(54-78)$ & $64(53-79)$ & $68(53-79)$ \\
APOE \&4 allele (\%) & $30(78.9)$ & $39(60.9)$ & $20(32.8)$ \\
MMSE (max. 30) & $23(16-27)$ & $28(23-30)$ & $30(28-30)$ \\
TMTA (s) & $60(32-300)$ & $51(23-146)$ & $43(23-75)$ \\
TMTB (s) & $161(107-255)$ & $109(72-330)$ & $94(40-240)$ \\
CERAD TWT, delayed recall & $1(0-5)$ & $3(0-8)$ & $7(3-10)$ \\
\hline
\end{tabular}

AD, Alzheimer's disease; MCI, mild cognitive impairment; TMTA, Trailmaking test A; TMTB, Trailmaking test B; TWT, Ten Word Test. Age, MMSE, TMTA, TMTB, and CERAD TWT delayed recall are given as median (range).

of the patients with amnestic MCI at baseline progressed to AD dementia, as described elsewhere [14]. It was subsequently possible to carry out an extended follow-up of the cohort, with a median time of 9 years (range 6-10 years). The clinical diagnosis after the initial study period and at the extended follow-up was determined by the same neurologists, and was based on information obtained from clinical interviews, examinations, and medical records. The neurologists were blind to biomarker results. The same criteria for amnestic MCI and AD dementia were applied as at baseline. Frontotemporal dementia (FTD) and vascular dementia were determined according to criteria according to Brun et al. [15] and Roman et al. [16] respectively.

\section{Sampling and analysis of CSF}

All participants underwent lumbar puncture at baseline. The procedure was usually carried out with the patient lying on their side, and CSF drawn at the L4/L5 intervertebral space. The pattern of CSF collection was the same for all study individuals, and usually performed early in the morning. The first $2.5 \mathrm{ml}$ CSF was used for non-research purposes, including routine clinical investigation. Subsequent CSF samples ( $1 \mathrm{ml}$ aliquots) were collected directly into $2 \mathrm{ml}$ polypropylene cryovials (Corning) immersed in ice-water. Samples were kept in ice-water while being sent for storage, and frozen within $30 \mathrm{~min}$ of lumbar puncture unless centrifuged to remove erythrocyte contamination [17, 18]. Erythrocyte counts in the remaining samples were (mean $\pm \mathrm{SD}$ ) $2.0 \pm 4.3$ erythrocytes $/ \mu 1 \mathrm{CSF}$, overall range $0-33$ erythrocytes/ $\mu 1 \mathrm{CSF}$, median 1 erythrocyte/ $\mu 1$ CSF. All samples were stored at $-80^{\circ} \mathrm{C}$ until analysis, when they were slowly thawed in ice-water on the morning of analysis, and therefore underwent only this single freeze-thaw treatment.

CSF samples were analyzed in duplicate by commercially available enzyme-linked immunosorbent assay (ELISA) monoplex kits according to the manufacturers' instructions from duplicate analyses. Biomarkers central to the $A / T / N$ classification $\left(A \beta_{42}\right.$, t-tau, and p-tau) were analyzed by ELISA (Fujirebio Innogenetics) as described previously [19]. Coefficients of variation for the amyloid and tau markers have been given elsewhere $[14,20]$.

\section{Statistical analysis and grouping according to the A/T/N classification}

Statistical analyses were carried out using SPSS version 25 (IBM). Normality was assessed through the inspection of QQ-plots, histograms, and the Shapiro-Wilks test of normality. CSF biomarkers had non-normal distributions, and group comparisons were carried out using the Kruskal-Wallis and MannWhitney U tests.

The healthy controls were significantly older than the patient groups at inclusion. The effect of age on analyte levels was examined by log-transforming the data to the natural logarithm to approximate a normal distribution, and applying a univariate linear model with age as co-variate. Since age was not found to affect the results presented here, it is not mentioned elsewhere in this article.

Assignment to $\mathrm{A} / \mathrm{T} / \mathrm{N}$ groups was based on cut-off levels of the core CSF biomarkers for $A D$, using $A \beta_{42}$ for ' $A$ ', p-tau for ' $T$ ' and t-tau as ' $\mathrm{N}$ '. The threshold levels were based retrospectively on the study material according to baseline CSF values in the AD dementia group compared to the healthy controls. After two-year 
Table 2

Levels of biomarkers in CSF at baseline

\begin{tabular}{lccc}
\hline Diagnosis & AD dementia & Amnestic MCI & Healthy individuals \\
\hline CSF A $\beta_{42} \mathrm{pg} / \mathrm{ml}$ & $457(212-1092)^{\mathrm{a}}$ & $567(173-1508)^{\mathrm{a}, \mathrm{b}}$ & $1013(434-1674)$ \\
CSF t-tau pg/ml & $612(177-3162)^{\mathrm{a}}$ & $418(99-2325)^{\mathrm{a}, \mathrm{b}}$ & $287(138-1314)$ \\
CSF p-tau pg/ml & $81(28-182)^{\mathrm{a}}$ & $67(16-169)^{\mathrm{b}}$ & $54(33-135)$ \\
\hline
\end{tabular}

AD, Alzheimer's disease; MCI, mild cognitive impairment; CSF, cerebrospinal fluid. CSF biomarkers are given as median (range). ${ }^{\mathrm{a}}$ Compared to healthy individuals, $p<0.01$. ${ }^{\mathrm{b}}$ Compared to AD dementia $p<0.01$.

follow-up none except one healthy control in these groups had changed diagnosis. Cut off values were calculated by maximizing Youden's index [(sensitivity + specificity)-1] [21]. A cut-off value between controls and patients with early AD dementia for CSF $A \beta_{42}$ from this material has previously been reported as $630 \mathrm{pg} / \mathrm{ml}$ [19]. Similarly, a cut-off level for CSF t-tau was calculated to be $394 \mathrm{pg} / \mathrm{ml}$ and for $\mathrm{p}$-tau to be $66 \mathrm{pg} / \mathrm{ml}$. Accordingly, CSF $\mathrm{A} \beta_{42}$ levels $<630 \mathrm{pg} / \mathrm{ml}$, t-tau levels $>394 \mathrm{pg} / \mathrm{ml}$, and p-tau levels $>66 \mathrm{pg} / \mathrm{ml}$ were considered pathological.

\section{RESULTS}

\section{Baseline biomarker levels in CSF}

The concentration of baseline CSF biomarkers in the clinical groups at inclusion are presented in Table 2. The concentration of $A \beta_{42}$ ("A") was significantly lower in the AD group compared to the amnestic MCI group, and less than half the concentration in the healthy control group (both $\mathrm{p}<0.01)$. It was also significantly lower in the amnestic MCI group compared to the controls $(\mathrm{p}<0.01)$. The median $A \beta_{42}$ concentrations in the $A D$ group and the amnestic MCI group at baseline were both below the calculated threshold level for $A \beta_{42}$ in this study $(<630 \mathrm{pg} / \mathrm{ml})$.

The concentration of p-tau ("T") in CSF was significantly higher in the $\mathrm{AD}$ group compared to the amnestic MCI group and the controls (both $\mathrm{p}<0.01$ ). However, there was no significant difference in the CSF concentration of p-tau between the amnestic MCI and control groups. Nevertheless, median ptau concentrations in both the AD and amnestic MCI groups at baseline were above the calculated threshold in this study $(>66 \mathrm{pg} / \mathrm{ml})$.

Similarly, the concentration of t-tau ("N") in CSF was significantly higher in the AD group compared to the amnestic MCI group and controls (both $\mathrm{p}<0.01$ ), though the t-tau concentration was also significantly higher in the amnestic MCI group compared to controls $(\mathrm{p}<0.01)$. Again, median $\mathrm{t}$-tau concentrations in the $\mathrm{AD}$ and amnestic MCI groups at baseline were both above the calculated threshold level for this study (>394 pg/ml).

\section{A retrospective application of $A / T / N$ to the clinical groups at baseline}

Figure 1 shows how individuals in the various clinical groups were distributed within the A/T/N classification system at baseline. Individuals classified as amyloid-positive $(\mathrm{A}+)$ were much more frequent in the patient groups: $89.9 \%$ in $\mathrm{AD}$ demen$\operatorname{tia}(\mathrm{A}+\mathrm{T}+\mathrm{N}+=26, \mathrm{~A}+\mathrm{T}-\mathrm{N}-=7, \mathrm{~A}+\mathrm{T}-\mathrm{N}+=1)$ and $62.5 \%$ of those with amnestic $\mathrm{MCI}(\mathrm{A}+\mathrm{T}+\mathrm{N}+=25$, $\mathrm{A}+\mathrm{T}-\mathrm{N}-=11, \mathrm{~A}+\mathrm{T}+\mathrm{N}-=2$ and $\mathrm{A}+\mathrm{T}-\mathrm{N}+=2)$, but only $8.2 \%$ of controls $(\mathrm{A}+\mathrm{T}+\mathrm{N}+=4$ and $\mathrm{A}+\mathrm{T}$ $\mathrm{N}-=1$ ). Individuals classified as amyloid negative (A-) were most frequent in the control group $(91.8 \%$, $\mathrm{A}-\mathrm{T}-\mathrm{N}-=42, \mathrm{~A}-\mathrm{T}+\mathrm{N}+=8$ and $\mathrm{A}-\mathrm{T}+\mathrm{N}-=6$ ), and $37.5 \%$ of those with amnestic MCI (A-T-N- $=15$, A$\mathrm{T}+\mathrm{N}+=6, \mathrm{~A}-\mathrm{T}+\mathrm{N}-=1$ and $\mathrm{A}-\mathrm{T}-\mathrm{N}+=2$ ), but only $10.5 \%$ of individuals $\mathrm{AD}$ dementia $(\mathrm{A}-\mathrm{T}-\mathrm{N}-=1$, A$\mathrm{T}+\mathrm{N}+=2$ and $\mathrm{A}-\mathrm{T}-\mathrm{N}+=1$ ).

\section{Sensitivity and specificity of the A/T/N classification of $A D$ dementia at baseline compared to cognitively healthy control individuals at baseline}

When a comparison was made between biomarker triple positive $(\mathrm{A}+\mathrm{T}+\mathrm{N}+)$ against biomarker triple negative (A-T-N-) in the affected (AD dementia) versus healthy (control) group, both sensitivity and specificity were over $90 \%$. Individual assessment of the biomarkers showed best sensitivity and specificity for amyloid (A), around 90\%. Neither T nor N were as sensitive or specific as amyloid. The data are shown in Table 3. 


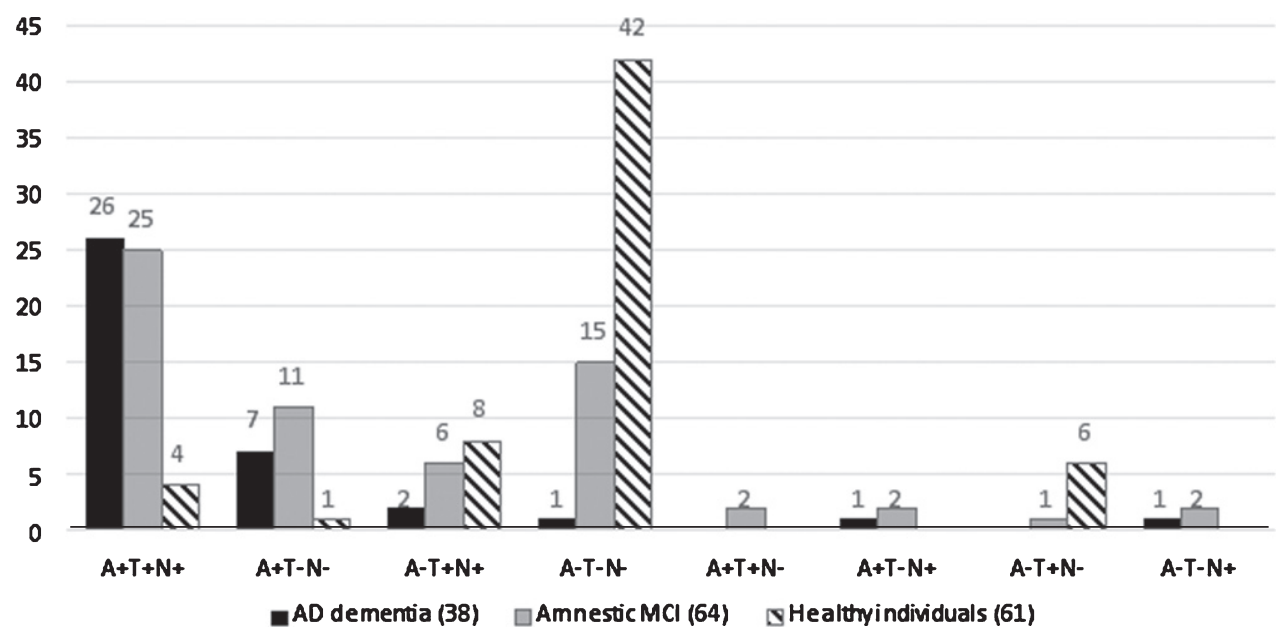

Fig. 1. A retrospective application of A/T/N to the clinical groups at baseline. AD, Alzheimer's disease; MCI, mild cognitive impairment. The figures over the histogram columns represent the number of individuals.

Table 3

Sensitivity and specificity of the $\mathrm{A} / \mathrm{T} / \mathrm{N}$ classification of $\mathrm{AD}$ dementia at baseline compared to cognitively healthy control individuals at baseline

\begin{tabular}{lcc}
\hline & Sensitivity & Specificity \\
\hline $\mathrm{A}$ & $89.9 \%$ & $91.8 \%$ \\
$\mathrm{~T}$ & $73.7 \%$ & $70.5 \%$ \\
$\mathrm{~N}$ & $78.9 \%$ & $80.3 \%$ \\
\hline
\end{tabular}

When all individuals in these two groups classified as $\mathrm{A}+\mathrm{T}+\mathrm{N}+$ were compared to all those classified as A-T-N-, the sensitivity was $96.3 \%$ and specificity was $91.3 \%$. Data were based on CSF levels of amyloid- $\beta_{42}(\mathrm{~A})$, phosphorylated tau (T), and total tau (N).

\section{Retrospective application of the A/T/N} classification system to the $A D$ group at baseline compared to clinical status after the extended follow-up period

The results of the $\mathrm{A} / \mathrm{T} / \mathrm{N}$ classification system, and clinical status after the extended follow-up period compared to baseline, are presented in Table 4. Only $\mathrm{A}+\mathrm{T}+\mathrm{N}+, \mathrm{A}+\mathrm{T}-\mathrm{N}-, \mathrm{A}-\mathrm{T}+\mathrm{N}+$, and $\mathrm{A}-\mathrm{T}-\mathrm{N}-$ were included in the Table because of low numbers in other combinations (given in the Table legend). All patients diagnosed with $\mathrm{AD}$ dementia at baseline kept this diagnosis during a median follow-up of 8 years (range 6-10 years).

Twenty-one of 25 amnestic MCI patients classified as $\mathrm{A}+\mathrm{T}+\mathrm{N}+$ at baseline had progressed to $\mathrm{AD}$ dementia during the follow-up period, while only two remained stable. However, these two had been recruited late in the inclusion period and had a followup time of only 6 years. One patient with amnestic MCI classified as $\mathrm{A}+\mathrm{T}+\mathrm{N}+$ had progressed clini- cally to FTD, and one had died before the two-year follow-up.

Of the 11 patients with amnestic MCI at baseline and subsequently classified as A + T-N-, five had progressed to $\mathrm{AD}$ dementia during the extended period, three remained stable, one was diagnosed with severe epilepsy, and two could not be traced.

Six patients with amnestic MCI at baseline were classified as $\mathrm{A}-\mathrm{T}+\mathrm{N}+$. Of these, five progressed to $\mathrm{AD}$ dementia and one remained stable during extended follow-up.

Fifteen of the amnestic MCI patients at baseline were classified as A-T-N-. After extended followup, four of these patients had remained stable, three had progressed to AD dementia, four were diagnosed with FTD or vascular dementia, one died before the two-year follow-up, two were classified as being cognitively healthy, while the last could not be traced.

Of the 42 healthy controls at baseline that were classified as A-T-N-, 40 remained cognitively healthy and two were lost to follow-up over a median of 9 years (range 7-10). Eight controls were classified as $\mathrm{A}-\mathrm{T}+\mathrm{N}+$ at baseline, of whom three remained cognitively healthy, one progressed to amnestic MCI and one to $\mathrm{AD}$ dementia, one had died before the two-year follow-up and two could not be traced. Of four classified as $\mathrm{A}+\mathrm{T}+\mathrm{N}+$ at baseline, two progressed to $\mathrm{AD}$ dementia, one had died before the two year follow-up, and one remained cognitively healthy during extended follow-up. Only one control individual was classified as A+ T-N-, and developed amyotrophic lateral sclerosis within a year of inclusion. No motor symptoms were present at baseline. 
Table 4

A/T/N classification applied to clinical groups at baseline compared to clinical status in 2019

\begin{tabular}{|c|c|c|c|c|c|c|}
\hline \multirow[t]{2}{*}{$\begin{array}{l}\mathrm{A} / \mathrm{T} / \mathrm{N} \\
\text { classification }\end{array}$} & \multicolumn{3}{|c|}{$\begin{array}{c}\text { Diagnosis at inclusion } \\
2009-2013\end{array}$} & \multicolumn{3}{|c|}{$\begin{array}{l}\text { Diagnosis at follow-up in } \\
\text { compared to inclusion }\end{array}$} \\
\hline & $\mathrm{AD}$ & $\mathrm{aMCI}$ & Controls & $\mathrm{AD}$ & aMCI & Controls \\
\hline & $n=38$ & $n=64$ & $n=61$ & $n=38$ & $n=64$ & $n=61$ \\
\hline $\mathrm{A}+\mathrm{T}+\mathrm{N}+$ & 26 & 25 & 4 & $26 \mathrm{AD}^{*}$ & $\begin{array}{l}21 \mathrm{AD}^{* *} \\
2 \mathrm{aMCI} \\
1 \mathrm{FTD} \\
1 \mathrm{DBD}\end{array}$ & $\begin{array}{l}1 \text { control } \\
2 \mathrm{AD} \\
1 \mathrm{DBD}\end{array}$ \\
\hline $\mathrm{A}+\mathrm{T}-\mathrm{N}-$ & 7 & 11 & 1 & $7 \mathrm{AD}$ & $\begin{array}{l}5 \text { AD } \\
3 \text { aMCI } \\
1 \text { epilepsy } \\
2 \text { LTF }\end{array}$ & $1 \mathrm{ALS}$ \\
\hline $\mathrm{A}-\mathrm{T}+\mathrm{N}+$ & 2 & 6 & 8 & $2 \mathrm{AD}$ & $\begin{array}{l}5 \mathrm{AD} \\
1 \mathrm{aMCI}\end{array}$ & $\begin{array}{l}3 \text { controls } \\
1 \mathrm{AD} \\
1 \mathrm{aMCI} \\
1 \mathrm{DBD} \\
2 \mathrm{LTF}\end{array}$ \\
\hline A-T-N- & 1 & 15 & 42 & $1 \mathrm{AD}$ & $\begin{array}{l}3 \mathrm{AD} \\
4 \mathrm{aMCI} \\
2 \mathrm{FTD}^{* * *} \\
2 \mathrm{VaD}^{* * *} \\
2 \text { healthy } \\
1 \text { DBD } \\
1 \mathrm{LTF}\end{array}$ & $\begin{array}{l}40 \text { controls } \\
2 \text { LTF }\end{array}$ \\
\hline
\end{tabular}

$\mathrm{AD}$, Alzheimer's disease dementia; aMCI, amnestic mild cognitive impairment; controls, cognitively healthy elderly control individuals; FTD, frontotemporal dementia; VaD, vascular dementia; DBD, died before diagnosis at two year follow up; LTF, lost to extended follow-up. Includes ${ }^{*} 16$ individuals; ${ }^{* *}$ five individuals; ${ }^{* * *}$ one individual that died during extended follow-up. $A / T / N$ was based on CSF concentrations of $A=$ amyloid- $\beta_{42}$, $\mathrm{T}=$ hyperphosphorylated tau, and $\mathrm{N}=$ total tau protein. The cut-off for amyloid- $\beta_{42}$ was calculated as $630 \mathrm{pg} / \mathrm{ml}$ and levels lower than this were considered to be $\mathrm{A}+$. The cut-off for hyperphosphorylated tau was $66 \mathrm{pg} / \mathrm{ml}$ and for total tau $394 \mathrm{pg} / \mathrm{ml}$. Levels higher than these were considered respectively $\mathrm{T}+$ and $\mathrm{N}+$. Combinations that were excluded due to low $\mathrm{n}$ were: $\mathrm{A}+\mathrm{T}+\mathrm{N}-(2 \mathrm{aMCI}), \mathrm{A}+\mathrm{T}-\mathrm{N}+(1 \mathrm{AD}, 2 \mathrm{aMCI}), \mathrm{A}-\mathrm{T}+\mathrm{N}-(1 \mathrm{aMCI}, 6 \mathrm{controls})$ and A-T-N+ (1 AD, 2 aMCI).

\section{DISCUSSION}

In this study we used the clinical diagnosis after six to ten years of follow-up as the gold standard independent of biomarkers for AD dementia, amnestic $\mathrm{MCI}$, and healthy controls, for a retrospective comparison with the $\mathrm{A} / \mathrm{T} / \mathrm{N}$ classification. CSF values of $A \beta_{42}$ ("A" for amyloid), phosphorylated tau ("T" for tau), and total tau ("N" for neurodegeneration) were used [7]. The A/T/N system is recommended for research purposes only, but it is still of interest to see how it would be represented in a clinical cohort, and to explore its application in a diagnostic setting. The concept of the A/T/N system was only possible because numerous studies have identified typical changes in brain pathology and CSF during the development of $\mathrm{AD}$. It is therefore unsurprising that most triple positive cases $(\mathrm{A}+\mathrm{T}+\mathrm{N}+)$ were found in the group of patients with $\mathrm{AD}$ dementia at baseline (where only four of 38 cases were amyloid negative), and in patients with amnestic MCI who converted to $\mathrm{AD}$ dementia during the initial study period or subsequent follow-up. Similarly, there was a large predominance of triple negative cases (A-T-N-) among cognitively-healthy control individuals.

The prevalence of suspected non-Alzheimer disease pathophysiology (SNAP) at baseline was relatively consistent across clinical groups (controls 13\%, amnestic MCI 9\%, and AD dementia $5 \%)$ and correlates well with other studies [22, 23]. These individuals had tau pathology $(\mathrm{T}+)$ and/or neurodegeneration $(\mathrm{N}+)$, but lacked amyloid deposition (A-), thereby distinguishing them from the typical biomarker profile of AD [24]. They often receive a clinical AD diagnosis, and in this study five of six individuals with amnestic MCI at baseline with $\mathrm{A}-\mathrm{T}+\mathrm{N}+$ progressed to $\mathrm{AD}$ dementia. The average level of $A \beta_{42}$ in the $A-T+N+(816 \mathrm{pg} / \mathrm{ml})$ group was much higher than the threshold for $\mathrm{A} \beta_{42}$ in this study. Autopsy studies have shown poor correspondence between clinical and neuropathological diagnosis, and up to one third of patients diagnosed as clinical AD showed mixed pathologies for AD, Lewy body disease, and vascular disease. Such pathologies 
can therefore cause dementia and amnestic MCI that mimic AD, also in the absence of amyloid pathology [25-27]. It has also been suggested that in some patients changes in tau metabolism may precede amyloid accumulation in AD [28, 29], even though the amyloid response usually occurs first [30].

A related concept has been termed primary agerelated tauopathy (PART). It is characterized by medial-temporal neurofibrillary pathology with few or no amyloid deposits, and is mostly seen among aged cognitively healthy individuals. PART can also be present in cognitively impaired individuals and is clinically diagnosed as AD in up to half the cases. Some claim PART is a pathologic entity distinct from $\mathrm{AD}$, while others see it as a part of the AD spectrum $[31,32]$. Our results are further support that pathological changes in amyloid metabolism are not requisite for the development of clinical AD.

The proportion of individuals with A-T-N- at baseline decreased with diagnostic severity, being most common among the controls. Indeed, none that could be traced had cognitive decline at extended followup, suggesting that the absence of all three biomarkers has good prognostic value for not developing dementia [33]. However, this only seems to be true for the controls in this study cohort. Individuals with amnestic MCI classified as A-T-N- at baseline had the most heterogenous clinical outcome in the longer term, including cases of FTD and vascular dementia, as well as remaining stable amnestic MCI or regaining healthy cognitive status. Twenty percent of those with amnestic MCI who were A-T-N- at baseline developed clinical AD dementia during extended follow-up. A study applying the A/T/N classification to a group of individuals in the Alzheimer's Disease Neuroimaging Initiative (ADNI) cohort found that $8 \%$ with amnestic MCI who were classified as A-T-Nat baseline developed AD dementia after 36 months. This is a lower percentage than found in the present study, but the follow-up period was much shorter [34].

Individuals with amnestic MCI who were triple negative might have been expected to be a group containing most individuals with stable amnestic MCI or regaining healthy cognitive status after extended follow-up. This was not the case. Almost half of the A-T-N-individuals in this group developed some type of dementia during follow-up. Our results therefore suggest that A-T-N- has a different prognosis depending on whether the individual is cognitively healthy or has an amnestic MCI phenotype at baseline.

Taken together it is clear that the amnestic MCI group was by far the most diverse and interesting group in this study. Although they all had a similar phenotype at the outset, they were heterogenous in the longer term both as to how they sorted into the $\mathrm{A} / \mathrm{T} / \mathrm{N}$ classification, as well as their final clinical outcome within the classification groups.

The main advantage of this study was the possibility to carry out a long-term follow-up of a high proportion of study individuals in a cohort were clinical diagnoses were independent of biomarkers. Additionally, the same two neurologists evaluated all participants and carried out all diagnostic procedures. This improved the continuity of the study and only $4 \%$ were lost to follow-up. Since all participants were followed over such a long period it was not possible either in terms of manpower or finances to include more participants, which is perhaps the main limitation of this study. Classifying $\mathrm{A} / \mathrm{T} / \mathrm{N}$ with biomarkers determined in CSF is a highly cost-effective procedure since a single lumbar puncture is cheaper than expensive imaging techniques. However, implementing different imaging techniques included in the $\mathrm{A} / \mathrm{T} / \mathrm{N}$ framework might improve the accuracy of the classification and possibly increase its diagnostic sensitivity and specificity further in this study.

\section{CONCLUSION}

The $\mathrm{A} / \mathrm{T} / \mathrm{N}$ system has the advantage of being unbiased and independent of clinical status and gives the possibility to study a clinical cohort by its pathophysiology. When selecting individuals for research, a combination of clinical evaluation and biomarkers may still be needed.

\section{ACKNOWLEDGMENTS}

We are indebted to our patients and their proxies as well as the control individuals who have enthusiastically supported this project over so many years. The project was supported by the Liaison Committee between the Central Norway Regional Health Authority and NTNU (grant number 90158101) as a part of the Dementia Disease Initiation.

Authors' disclosures available online (https:// www.j-alz.com/manuscript-disclosures/19-1227r1).

\section{REFERENCES}

[1] Brookmeyer R, Johnson E, Ziegler-Graham K, Arrighi HM (2007) Forecasting the global burden of Alzheimer's disease. Alzheimers Dement 3, 186-191. 
[2] Bateman RJ, Xiong C, Benzinger TL, Fagan AM, Goate A, Fox NC, Marcus DS, Cairns NJ, Xie X, Blazey TM, Holtzman DM, Santacruz A, Buckles V, Oliver A, Moulder K, Aisen PS, Ghetti B, Klunk WE, McDade E, Martins RN, Masters CL, Mayeux R, Ringman JM, Rossor MN, Schofield PR, Sperling RA, Salloway S, Morris JC, Dominantly Inherited Alzheimer N (2012) Clinical and biomarker changes in dominantly inherited Alzheimer's disease. $N$ Engl J Med 367, 795-804.

[3] Fagan AM, Xiong C, Jasielec MS, Bateman RJ, Goate AM, Benzinger TL, Ghetti B, Martins RN, Masters CL, Mayeux R, Ringman JM, Rossor MN, Salloway S, Schofield PR, Sperling RA, Marcus D, Cairns NJ, Buckles VD, Ladenson JH, Morris JC, Holtzman DM, Dominantly Inherited Alzheimer N (2014) Longitudinal change in CSF biomarkers in autosomal-dominant Alzheimer's disease. Sci Transl Med 6, 226ra230.

[4] Petersen RC (2004) Mild cognitive impairment as a diagnostic entity. J Intern Med 256, 183-194.

[5] Sperling RA, Aisen PS, Beckett LA, Bennett DA, Craft S, Fagan AM, Iwatsubo T, Jack CR Jr., Kaye J, Montine TJ, Park DC, Reiman EM, Rowe CC, Siemers E, Stern Y, Yaffe K, Carrillo MC, Thies B, Morrison-Bogorad M, Wagster MV, Phelps CH (2011) Toward defining the preclinical stages of Alzheimer's disease: Recommendations from the National Institute on Aging-Alzheimer's Association workgroups on diagnostic guidelines for Alzheimer's disease. Alzheimers Dement 7, 280-292.

[6] Knopman DS, Haeberlein SB, Carrillo MC, Hendrix JA, Kerchner G, Margolin R, Maruff P, Miller DS, Tong G, Tome MB, Murray ME, Nelson PT, Sano M, Mattsson N, Sultzer DL, Montine TJ, Jack CR Jr., Kolb H, Petersen RC, Vemuri P, Canniere MZ, Schneider JA, Resnick SM, Romano G, van Harten AC, Wolk DA, Bain LJ, Siemers E (2018) The National Institute on Aging and the Alzheimer's Association Research Framework for Alzheimer's disease: Perspectives from the Research Roundtable. Alzheimers Dement 14, 563575.

[7] Jack CR Jr., Bennett DA, Blennow K, Carrillo MC, Feldman HH, Frisoni GB, Hampel H, Jagust WJ, Johnson KA, Knopman DS, Petersen RC, Scheltens P, Sperling RA, Dubois B (2016) A/T/N: An unbiased descriptive classification scheme for Alzheimer disease biomarkers. Neurology 87, 539-547.

[8] McKhann G, Drachman D, Folstein M, Katzman R, Price D, Stadlan EM (1984) Clinical diagnosis of Alzheimers disease Report of the NINCDS-ADRDA work group under the auspices of department of health and human services task force on Alzheimer's disease. Neurology 34, 939-944.

[9] Winblad B, Palmer K, Kivipelto M, Jelic V, Fratiglioni L, Wahlund LO, Nordberg A, Backman L, Albert M, Almkvist O, Arai H, Basun H, Blennow K, de Leon M, DeCarli C, Erkinjuntti T, Giacobini E, Graff C, Hardy J, Jack C, Jorm A, Ritchie K, van Duijn C, Visser P, Petersen RC (2004) Mild cognitive impairment-beyond controversies, towards a consensus: Report of the International Working Group on Mild Cognitive Impairment. J Intern Med 256, 240-246.

[10] Folstein MF, Folstein SE, McHugh PR (1975) Mini-Mental State: A practical method for grading the cognitive state of patients for clinician. J Psychol Res 12, 189-198.

[11] Rosen WG, Mohs RC, Davis KL (1984) A new rating scale for Alzheimer's disease. Am J Psychiatry 141, 1356-1364.

[12] Reitan RM (1958) Validity of the Trail Making Test as an indication of organic brain damage. Percept Mot Skills 8 , 271-276.
[13] Berge G, Sando SB, Rongve A, Aarsland D, White LR (2014) Apolipoprotein E epsilon2 genotype delays onset of dementia with Lewy bodies in a Norwegian cohort. J Neurol Neurosurg Psychiatry 85, 1227-1231.

[14] Lauridsen C, Sando SB, Shabnam A, Moller I, Berge G, Grontvedt GR, Bakken IJ, Salvesen O, Brathen G, White LR (2016) Cerebrospinal fluid levels of amyloid beta 1-43 in patients with amnestic mild cognitive impairment or early Alzheimer's disease: A 2-year follow-up study. Front Aging Neurosci 8, 30.

[15] (1994) Clinical and neuropathological criteria for frontotemporal dementia. The Lund and Manchester Groups. J Neurol Neurosurg Psychiatry 57, 416-418.

[16] Roman GC, Tatemichi TK, Erkinjuntti T, Cummings JL, Masdeu JC, Garcia JH, Amaducci L, Orgogozo JM, Brun A, Hofman A, et al. (1993) Vascular dementia: Diagnostic criteria for research studies. Report of the NINDS-AIREN International Workshop. Neurology 43, 250-260.

[17] Bjerke M, Portelius E, Minthon L, Wallin A, Anckarsater $\mathrm{H}$, Anckarsater R, Andreasen N, Zetterberg H, Andreasson U, Blennow K (2010) Confounding factors influencing amyloid Beta concentration in cerebrospinal fluid. Int $J$ Alzheimers Dis 2010, 986310.

[18] Simonsen AH, Bahl JM, Danborg PB, Lindstrom V, Larsen SO, Grubb A, Heegaard NH, Waldemar G (2013) Preanalytical factors influencing the stability of cerebrospinal fluid proteins. J Neurosci Methods 215, 234-240.

[19] Berge G, Lauridsen C, Sando SB, Holder DJ, Moller I, Aasly JO, Brathen G, Savage MJ, White LR (2016) Effect of Tween- 20 on core biomarkers measured in cerebrospinal fluid from patients with Alzheimer's disease, mild cognitive impairment, or healthy control individuals. J Alzheimers Dis 49, 493-502.

[20] Berge G, Lauridsen C, Sando SB, Holder D, Moller I, Aasly JO, Brathen G, Savage M, White LR (2015) Effect of Tween20 on core biomarkers measured in cerebrospinal fluid from patients with Alzheimer's disease, mild cognitive impairment, or healthy control individuals. J Alzheimers Dis $\mathbf{4 9}$, 493-502.

[21] Youden WJ (1950) Index for rating diagnostic tests. Cancer 3, 32-35.

[22] Altomare D, de Wilde A, Ossenkoppele R, Pelkmans W, Bouwman F, Groot C, van Maurik I, Zwan M, Yaqub M, Barkhof F, van Berckel BN, Teunissen CE, Frisoni GB, Scheltens P, van der Flier WM (2019) Applying the ATN scheme in a memory clinic population: The ABIDE project. Neurology 93, e1635-e1646.

[23] Carandini T, Arighi A, Sacchi L, Fumagalli GG, Pietroboni AM, Ghezzi L, Colombi A, Scarioni M, Fenoglio C, De Riz MA, Marotta G, Scarpini E, Galimberti D (2019) Testing the 2018 NIA-AA research framework in a retrospective large cohort of patients with cognitive impairment: From biological biomarkers to clinical syndromes. Alzheimers Res Ther $\mathbf{1 1}, 84$.

[24] Jack CR Jr., Knopman DS, Chetelat G, Dickson D, Fagan AM, Frisoni GB, Jagust W, Mormino EC, Petersen RC, Sperling RA, van der Flier WM, Villemagne VL, Visser PJ, Vos SJ (2016) Suspected non-Alzheimer disease pathophysiology-concept and controversy. Nat Rev Neurol 12, 117-124.

[25] Petersen RC, Aisen P, Boeve BF, Geda YE, Ivnik RJ, Knopman DS, Mielke M, Pankratz VS, Roberts R, Rocca WA, Weigand S, Weiner M, Wiste H, Jack Jr CR (2013) Mild cognitive impairment due to Alzheimer disease in the community. Ann Neurol 74, 199-208. 
[26] Scheltens P (2013) Mild cognitive impairment—amyloid and beyond. Nat Rev Neurol 9, 493.

[27] Abner EL, Kryscio RJ, Schmitt FA, Fardo DW, Moga DC, Ighodaro ET, Jicha GA, Yu L, Dodge HH, Xiong C, Woltjer RL, Schneider JA, Cairns NJ, Bennett DA, Nelson PT (2017) Outcomes after diagnosis of mild cognitive impairment in a large autopsy series. Ann Neurol 81, 549-559.

[28] Braak H, Braak E (1991) Neuropathological stageing of Alzheimer-related changes. Acta Neuropathol 82, 239-259.

[29] Chetelat G (2013) Alzheimer disease: Abeta-independent processes-rethinking preclinical AD. Nat Rev Neurol 9, 123124.

[30] Jack CR Jr., Knopman DS, Jagust WJ, Shaw LM, Aisen PS, Weiner MW, Petersen RC, Trojanowski JQ (2010) Hypothetical model of dynamic biomarkers of the Alzheimer's pathological cascade. Lancet Neurol 9, 119-128.

[31] Duyckaerts C, Braak H, Brion JP, Buee L, Del Tredici K, Goedert M, Halliday G, Neumann M, Spillantini MG, Tolnay M, Uchihara T (2015) PART is part of Alzheimer disease. Acta Neuropathol 129, 749-756.
[32] Teylan M, Besser LM, Crary JF, Mock C, Gauthreaux K, Thomas NM, Chen YC, Kukull WA (2019) Clinical diagnoses among individuals with primary age-related tauopathy versus Alzheimer's neuropathology. Lab Invest 99, $1049-1055$.

[33] Olsson B, Lautner R, Andreasson U, Ohrfelt A, Portelius E, Bjerke M, Holtta M, Rosen C, Olsson C, Strobel G, Wu E, Dakin K, Petzold M, Blennow K, Zetterberg H (2016) CSF and blood biomarkers for the diagnosis of Alzheimer's disease: A systematic review and meta-analysis. Lancet Neurol 15, 673-684.

[34] Ekman U, Ferreira D, Westman E (2018) The A/T/N biomarker scheme and patterns of brain atrophy assessed in mild cognitive impairment. Sci Rep 8, 8431. 